\title{
Risk of incident clinical diagnosis of Alzheimer's disease-type dementia attributable to pathology-confirmed vascular disease
}

\author{
Hiroko H. Dodge ${ }^{\mathrm{a}, \mathrm{b}, *}$, Jian Zhu ${ }^{\mathrm{c}}$, Randy Woltjer $^{\mathrm{a}}$, Peter T. Nelson ${ }^{\mathrm{d}, \mathrm{e}}$, David A. Bennett ${ }^{\mathrm{f}, \mathrm{g}}$, \\ Nigel J. Cairns ${ }^{\mathrm{h}, \mathrm{i}}$, David W. Fardo ${ }^{\mathrm{d}, \mathrm{j}}$, Jeffrey A. Kaye ${ }^{\mathrm{a}, \mathrm{k}}$, Deniz-Erten Lyons ${ }^{\mathrm{a}, \mathrm{k}}$, Nora Mattek ${ }^{\mathrm{a}}$, \\ Julie A. Schneider ${ }^{\mathrm{f}, \mathrm{g}, \mathrm{l}}$, Lisa C. Silbert ${ }^{\mathrm{a}, \mathrm{k}}$, Chengjie Xiong ${ }^{\mathrm{h}}$, Lei $\mathrm{Yu}^{\mathrm{f}, \mathrm{g}}$, Frederick A. Schmitt ${ }^{\mathrm{d}, \mathrm{m}}$, \\ Richard J. Kryscio ${ }^{\mathrm{d}, \mathrm{j}}$, Erin L. Abner ${ }^{\mathrm{d}, \mathrm{n}}$, and the SMART data consortium \\ ${ }^{a}$ Layton Aging and Alzheimer's Disease Center, Department of Neurology, Oregon Health \& Science University, Portland, OR \\ ${ }^{b}$ Michigan Alzheimer's Disease Center, Department of Neurology, University of Michigan, Ann Arbor, MI \\ ${ }^{c}$ School of Public Health, Department of Biostatistics, University of Michigan, Ann Arbor, MI \\ ${ }^{d}$ Sanders-Brown Center on Aging, University of Kentucky, Lexington, $K Y$ \\ ${ }^{e}$ Department of Pathology, University of Kentucky, Lexington, $K Y$ \\ ${ }^{f}$ Rush Alzheimer's Disease Center, Rush University Medical Center, Chicago, IL \\ ${ }^{g}$ Department of Neurological Sciences, Rush University Medical Center, Chicago, IL \\ ${ }^{h}$ Knight Alzheimer's Disease Research Center, Department of Neurology, Washington University School of Medicine, St. Louis, MO \\ ${ }^{i}$ Department of Pathology and Immunology, Washington University School of Medicine, St. Louis, MO \\ ${ }^{j}$ College of Public Health, Department of Biostatistics, University of Kentucky, Lexington, KY \\ ${ }^{k}$ Portland VA Medical Center, Portland, OR \\ ${ }^{l}$ Department of Pathology, Rush University Medical Center, Chicago, IL \\ ${ }^{m}$ College of Medicine, Departments of Neurology and Psychiatry, University of Kentucky, Lexington, KY \\ ${ }^{n}$ College of Public Health, Department of Epidemiology, University of Kentucky, Lexington, $K Y$
}

\begin{abstract}
Introduction: The presence of cerebrovascular pathology may increase the risk of clinical diagnosis of Alzheimer's disease (AD).

Methods: We examined excess risk of incident clinical diagnosis of AD (probable and possible AD) posed by the presence of lacunes and large infarcts beyond AD pathology using data from the Statistical Modeling of Aging and Risk of Transition study, a consortium of longitudinal cohort studies with more than 2000 autopsies. We created six mutually exclusive pathology patterns combining three levels of AD pathology (low, moderate, or high AD pathology) and two levels of vascular pathology (without lacunes and large infarcts or with lacunes and/or large infarcts).

Results: The coexistence of lacunes and large infarcts results in higher likelihood of clinical diagnosis of AD only when AD pathology burden is low.

Discussion: Our results reinforce the diagnostic importance of AD pathology in clinical AD. Further harmonization of assessment approaches for vascular pathologies is required.

(C) 2016 the Alzheimer's Association. Published by Elsevier Inc. All rights reserved.
\end{abstract}

Keywords: $\quad$ Alzheimer's disease pathology; Vascular pathology; SMART consortium; Population Attributable Risk\%; Community sample

\section{Introduction}

Epidemiologic studies have shown that reducing vascular risk factors could yield large decreases in the prevalence of

*Corresponding author. Tel.: 724-494-3605; Fax: 503-494-7499.

E-mail address: dodgeh@ohsu.edu or Hiroko.dodge@gmail.com (H.H.D.) all-cause dementia [1,2] and Alzheimer's disease (AD) $[3,4]$. Studies have also shown the significance of vascular disease in the pathogenesis of $\mathrm{AD}[5-10]$ and that comorbid cerebrovascular pathology plays a key role for clinical expression of dementia, especially among the oldest old $[11,12]$ where mixed pathology is common $[13,14]$. 
Self-reported vascular disease or its risk factors used in most epidemiologic studies give important information regarding the potential contribution of these factors on risk of receiving a clinical diagnosis of probable or possible AD (henceforth "clinical AD" in this article), but a more precise assessment of etiology and factors associated with clinical AD may be provided by autopsy confirmed evidence. However, it is often difficult to obtain a large enough premorbidly characterized postmortem sample to allow examination of the magnitude of additional risks for clinical AD posed by coexisting vascular factors, especially among nonclinical cohorts. In this study, we used the Statistical Modeling of Aging and Risk of Transition (SMART) study, which is a consortium of high-quality longitudinal studies of aging and cognition, established for the purpose of characterizing risk and protective factors associated with subtypes of age-associated mixed neuropathologies [15]. Our aim was to quantify the excess risk of receiving a clinical $\mathrm{AD}$ diagnosis associated with the pathology-confirmed presence of lacunes (small artery infarcts) and one or more large artery cerebral infarct(s), beyond AD signature pathology defined by neuritic plaques scores [16] and Braak and Braak neurofibrillary tangle (NFT) stage [17]. We created six mutually exclusive pathology patterns: (1) low AD pathology without lacunes and large infarcts, (2) low AD pathology with lacunes and/or large infarcts, (3) moderate AD pathology without lacunes and large infarcts, (4) moderate AD pathology with lacunes and/or large infarcts, (5) high AD pathology without lacunes and large infarcts, and (6) high AD pathology with lacunes and/or large infarcts. The aim of this study is not to delineate the causal relationship between cerebrovascular factors and the development of hallmark AD pathologies, but rather to assess the Population Attributable Risk \% (PAR\%) of lacunes and large infarcts on having clinical $\mathrm{AD}$, that is, the proportion of clinical $\mathrm{AD}$ incidence that could be eliminated by preventing lacunes and large infarcts.

\section{Methods}

\subsection{Participants}

The SMART data consortium and the longitudinal cohort studies included in the data set are explained in detail elsewhere [15]. On the basis of the availability of necessary variables, participants from the following eight projects contributed by four centers in the USA were included in the present study: the Oregon Brain Aging Study I and II [18], the African American Dementia Project [15], and the Klamath Exceptional Aging Project [19] from Oregon Health \& Science University, Portland, Oregon; the Religious Orders Study [20] and the Rush Memory and Aging Project [21] from the Rush University, Chicago, Illinois; the Memory and Aging Project [22] from Washington University, St Louis, Missouri; and the Biologically Resilient Adults in Neurological Studies [23] from University of Kentucky, Lexington, Kentucky. We note that these four centers are Alzheimer's Disease Centers (ADCs), although the cohorts mentioned previously are recruited from communities. Institutional review boards at each research center approved all study procedures, and all participants provided written informed consent.

\subsection{Harmonization of variables}

SMART investigators reviewed data collection protocols from each participating center and identified elements that were common to at least two centers. Data templates, based on the methods established by the National Alzheimer's Coordinating Center [24], which aggregates data collected by ADCs, were developed to request standardized data elements from each center. Data templates for demographic information, genetics and family history of dementia, clinical diagnosis, motor function, medical history, medication use, physical examination, and neuropathology were the same for all centers. All centers used similar criteria for diagnoses of all-cause dementia (Diagnostic and Statistical Manual of Mental Disorders, Third Edition - Revised [25] or Diagnostic and Statistical Manual of Mental Disorders, Fourth Edition [26]) and clinical AD [27]. However, clinical diagnoses of mild cognitive impairment (MCI) were less standardized because some studies were initiated before MCI diagnostic criteria were established, and MCI diagnostic criteria have evolved over time. Therefore, in the present study, we are limiting our outcome of interest to $\mathrm{AD}$ and not to $\mathrm{MCI}$ or $\mathrm{MCI}$ due to $\mathrm{AD}$.

\subsection{Pathology variables}

Neuropathologic assessments were performed blind to clinical data. The component neuropathologic data were coded according to National Alzheimer's Coordinating Center guidelines, as described previously (see https://www.alz. washington.edu/nonmember/np/rdd_np.pdf). We created six mutually exclusive pathology patterns: (1) low AD pathology without lacunes and large infarcts, (2) low AD pathology with lacunes and/or large infarcts, (3) moderate AD pathology without lacunes and large infarcts, (4) moderate AD pathology with lacunes and/or large infarcts, (5) high AD pathology without lacunes and large infarcts, and (6) high AD pathology with lacunes and/or large infarcts. We used the Consortium to Establish a Registry in Alzheimer's Disease (CERAD) neuritic plaque rating [16] and Braak and Braak NFT stages [17] to define low, moderate, and high AD pathology. Low AD pathology was defined as Braak NFT stage of none, I, or II with CERAD plaque stage of none or sparse; high AD pathology was defined as Braak NFT Stage V or VI with CERAD plaque stage of moderate or frequent. Moderate $\mathrm{AD}$ pathology was defined as those cases falling between the low and high groups (details are shown in Table 1, discussed later). Large infarcts were defined as those with maximum diameter greater than $1 \mathrm{~cm}$ that were territorial in nature and attributed to compromise involving large- or medium-sized meningocerebral vessels; lacunes were defined as infarcts or hemorrhages $1 \mathrm{~cm}$ or less in 
Table 1

Pathology patterns and associated characteristics

\begin{tabular}{|c|c|c|c|c|c|c|c|c|c|c|c|c|c|c|c|}
\hline \multirow[b]{2}{*}{ Pathology patterns: $n \%$} & \multirow[b]{2}{*}{$\mathrm{N}(\%)$} & \multicolumn{2}{|c|}{$\begin{array}{l}\text { Braak (none or } \\
\text { Stage I or II) }\end{array}$} & \multicolumn{2}{|c|}{$\begin{array}{l}\text { Braak Stage } \\
\text { III or IV }\end{array}$} & \multicolumn{2}{|c|}{$\begin{array}{l}\text { Braak Stage } \\
\text { V or VI }\end{array}$} & \multicolumn{3}{|c|}{$\begin{array}{l}\text { Clinical diagnosis of probable or } \\
\text { possible } \mathrm{AD}\end{array}$} & \multicolumn{2}{|c|}{$\begin{array}{l}\text { Clinical diagnosis of } \\
\text { probable or possible } \\
\text { vascular dementia }\end{array}$} & \multicolumn{2}{|c|}{$\begin{array}{l}\text { Lewy body pathology } \\
\text { present }\end{array}$} & \multirow[b]{2}{*}{$\begin{array}{l}\text { APOE } \varepsilon 4 \\
\text { present }\end{array}$} \\
\hline & & $\begin{array}{l}\text { Plaque no } \\
\text { or sparse }\end{array}$ & $\begin{array}{l}\text { Plaque } \\
\text { moderate/ } \\
\text { frequent }\end{array}$ & $\begin{array}{l}\text { Plaque no } \\
\text { or sparse }\end{array}$ & $\begin{array}{l}\text { Plaque } \\
\text { moderate/ } \\
\text { frequent }\end{array}$ & $\begin{array}{l}\text { Plaque no } \\
\text { or sparse }\end{array}$ & $\begin{array}{l}\text { Plaque } \\
\text { moderate/ } \\
\text { frequent }\end{array}$ & All & $\begin{array}{l}\text { With PART } \\
(\% \text { of all })\end{array}$ & $\begin{array}{l}\text { Neocortical } \\
\text { Lewy body } \\
\text { (\% of all) }\end{array}$ & All & $\begin{array}{l}\text { With PART } \\
\text { (\% of all) }\end{array}$ & All & $\begin{array}{l}\text { Neocortical } \\
\text { Lewy body } \\
\text { (\% of all) }\end{array}$ & \\
\hline $\begin{array}{l}\text { (1) Low AD pathology } \\
\text { without lacunes and } \\
\text { large infarcts }\end{array}$ & $167(15.8)$ & 167 & 0 & 0 & 0 & 0 & 0 & $7(4.2)$ & 0 & $2(0.3)$ & $1(0.6)$ & 0 & $16(9.6)$ & $5(31.3)$ & $20(12.0)$ \\
\hline $\begin{array}{l}\text { (2) Low AD pathology } \\
\text { with lacunes and/or } \\
\text { large infarcts }\end{array}$ & $90(8.5)$ & 90 & 0 & 0 & 0 & 0 & 0 & $14(15.6)$ & 0 & 0 & $4(4.4)$ & 0 & $13(14.4)$ & $2(15.4)$ & $11(12.1)$ \\
\hline $\begin{array}{l}\text { (3) Moderate AD pathology } \\
\text { without lacunes and } \\
\text { large infarcts }\end{array}$ & $347(32.9)$ & 0 & 63 & 118 & 155 & 11 & 0 & 57 (16.4) & $16(28.1)$ & $11(19.2)$ & $12(3.5)$ & $2(16.7)$ & 69 (19.9) & 34 (49.3) & $74(21.3)$ \\
\hline $\begin{array}{l}\text { (4) Moderate AD pathology } \\
\text { with lacunes and/or } \\
\text { large infarcts }\end{array}$ & $267(25.3)$ & 0 & 36 & 86 & 136 & 0 & 0 & $71(25.6)$ & $17(23.9)$ & $11(15.4)$ & $23(8.6)$ & $7(30.4)$ & $52(19.5)$ & $21(40.4)$ & $52(19.5)$ \\
\hline $\begin{array}{l}\text { (5) High AD pathology } \\
\text { without lacunes and } \\
\text { large infarcts }\end{array}$ & $105(10.0)$ & 0 & 0 & 0 & 0 & 0 & 105 & $56(53.3)$ & 0 & $11(19.6)$ & $8(7.6)$ & 0 & $31(29.5)$ & $17(54.8)$ & $38(36.2)$ \\
\hline $\begin{array}{l}\text { (6) High AD pathology } \\
\text { with lacunes and/or } \\
\text { large infarcts }\end{array}$ & $78(7.4)$ & 0 & 0 & 0 & 0 & 0 & 78 & $40(51.3)$ & 0 & $9(22.5)$ & $12(15.4)$ & 0 & $23(29.5)$ & $12(52.2)$ & $38(48.7)$ \\
\hline Total & 1054 & & & & & & & 245 & 33 & 44 & 60 & 9 & 204 & 91 & 233 \\
\hline
\end{tabular}

Abbreviations: AD, Alzheimer's disease; PART, primary age-related tauopathy.

NOTE. Low AD pathology: Braak = no neurofibrillary degeneration present or Stage I or II; neuritic plaque = none or space. High AD pathology: Braak = Stage Vor VI; neuritic plaque = moderate or frequent. Moderate AD pathology: those not falling into the previously mentioned two categories. 
diameter because of small parenchymal vascular disease and most commonly encountered in the deep gray matter.

\subsection{Covariates}

Participant age at death (centered at 85 years), sex (female $=1$, male $=0$ ), years of education, apolipoprotein $\mathrm{E}(A P O E) \varepsilon 4$ carrier status (at least one $A P O E \varepsilon 4$ allele $=1$, no $A P O E \varepsilon 4$ alleles $=0$ ), Lewy body pathology presence (yes $=1$, no $=0$ ), and indicators for center (Rush, Kentucky, Washington University, with Oregon as the reference group) were considered.

\subsection{Statistical analyses}

We examined characteristics associated with having an autopsy (i.e., autopsy data not missing) to assess possible selection bias. Group differences (with or without autopsy) were examined first by univariate analysis using Student's $t$ test or Wilcoxon ranked sum test for continuous variables and the Pearson chi-square test for categorical variables, and then by multivariate analysis using a logistic regression model with the outcome being the presence or absence of autopsy data. The risks of developing a clinical diagnosis of AD associated with the six pathology patterns were examined using a Cox proportional hazards model with age as the time scale. To examine variability across centers, we ran the models with (Model 1) and without (Model 2) center indicators. Proportionality assumptions were examined through visual inspection of $\log -\log$ survival curves and analytical assessments [28] using covariates-by-time interactions in the Cox model. Using the coefficients obtained from the models and prevalence of each of the six pathology patterns, we estimated the PAR\%. PAR\% is determined by both the prevalence of a risk factor and the magnitude of its effect.

\subsection{Sensitivity analysis using multiple imputation approaches}

As a sensitivity analysis, we imputed missing pathology data using multiple imputation approaches and examined whether conclusions differed if we used the imputed data. Preliminary analyses showed that missingness among pathology data was dependent on observed data, and therefore we assumed that our data were missing at random (MAR [29]). To increase precision of imputed pathology patterns, we also imputed age of onset of dementia and clinical AD, if these data were missing. There were several challenges to our imputation approaches including the following: (1) missingness occurred in multiple different types of variables, including binary (yes/no) and continuous (e.g., age of onset) variables, (2) there were boundary restrictions, for example, age of clinical $\mathrm{AD}$ onset must occur later than the last observed date when a clinical diagnosis of normal cognition was provided, and (3) there were logical restrictions, for example, clinical AD onset could be imputed only if participants had dementia onset (either imputed or actually observed). Therefore, we applied a sequential regression multiple imputation (SRMI) approach [30-32], also known as multivariate imputation by chained equations [33], to impute these missing values. Briefly, the SRMI approach uses an iterative algorithm with a sequence of fully conditionally specified models. It is particularly useful in our study as SRMI can easily handle the challenges mentioned previously. The following variables were used in SRMI: completely observed variables (without missing data) used for imputation included gender, education, age at death, clinical diagnosis at last clinical assessment before death, duration of follow-up, duration between the last clinical assessment and death, center indicators and $A P O E \& 4$ information. Variables imputed sequentially included age at dementia onset, age at $\mathrm{AD}$ onset, and pathology variables (Braak and CERAD scores, Lewy body pathology, lacunes, and large infarcts). We closely monitored algorithm convergence as reported in Section 3. All analyses were conducted using statistical software $\mathrm{R}$ (version 3.1.3) and SAS 9.3 (SAS Institute, Inc, Cary, NC).

\section{Results}

Of 5405 participants with intact cognition at baseline, 1673 participants died (Fig. 1). Among them, 1566 participants had APOE information. Among them, 1054 participants had an autopsy with complete pathology information and were used in the primary analyses. Additional 512 participants with none or missing autopsy variables (Fig. 1) were also used for our sensitivity analysis where we imputed autopsy data. The mean (standard deviation, range) baseline age of the full sample ( $n=1566$ participants) was 79.7 years $(7.2,59.5-101.9)$, mean age at death was 88.5 years $(7.2,61.6-107.9)$, and $54.4 \%$ were women. Average observed duration of follow-up to death was 8.5 years (5.0) and average time from the last assessment to death was 1.6 years (2.1). Table 2 shows the characteristics of the participants with and without autopsy based on univariate analyses. Those without autopsy were older $(P=.01)$, more likely to be White (vs. non-White) $(P<.001)$, lower years of education $(P<.001)$, had shorter duration of follow-up $(P=.006)$, and longer duration between the last clinical assessment to death $(P<.001)$.

Table 1 shows the prevalence of the six pathology patterns, frequency of the NFT and plaque categories by pathology patterns, observed number of clinical diagnoses of $A D$ and vascular dementia, presence of Lewy body pathology, and the prevalence of $A P O E \varepsilon 4$ allele (proportion of subjects with at least one $\varepsilon 4$ allele) by the six pathology patterns. Moderate AD pathology (58\%) was the dominant pattern. We also provided separate columns for (1) neocortical Lewy body pathology [34,35] and (2) primary age-related tauopathy [36], which was defined here as CERAD plaque stage of none or sparse with Braak Stage of III or higher, because of the tendency of these pathologies to mimic the clinical symptoms of AD. About $23 \%$ of subjects in this study (245 of 1054) had a clinical AD diagnosis during follow-up, and 6\% (60 of 1054) were diagnosed with 


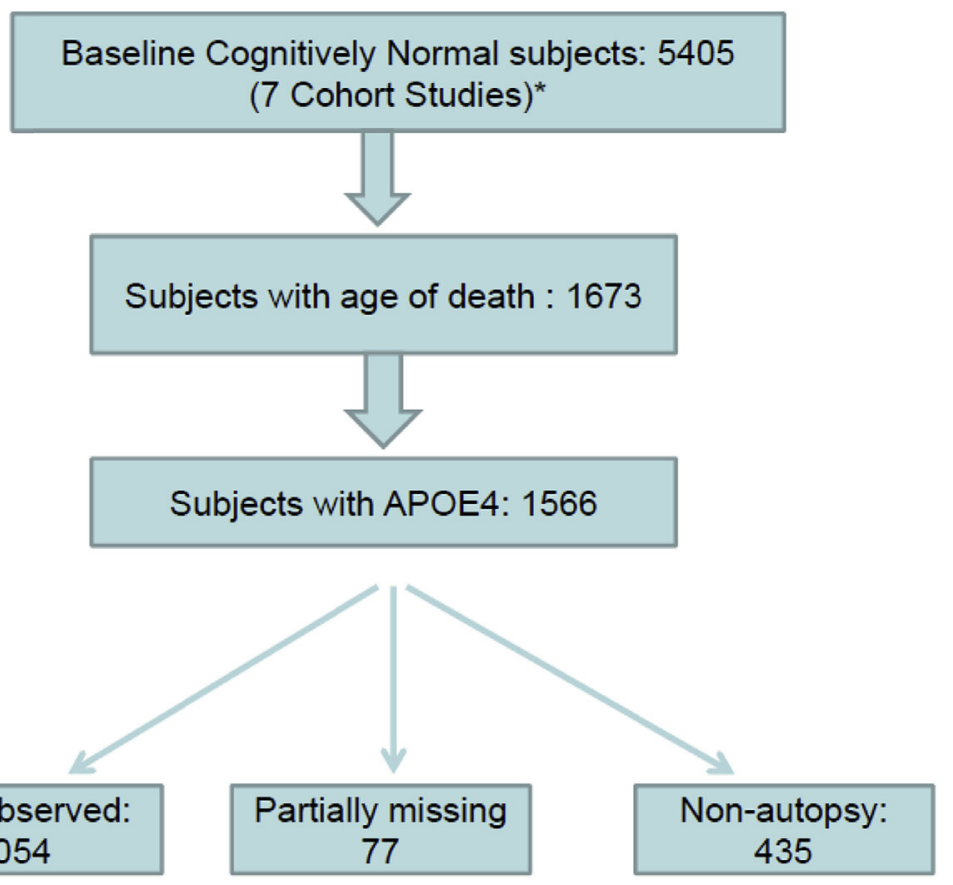

Fig. 1. Sample size flow chart. *Study cohorts included in the present study: MAPWU (Memory and Aging Project [Washington University, USA]); OBAS (Oregon Brain Aging Study I and II); AADAPt (African American Dementia and Aging Project); KEAP (Klamath Exceptional Aging Project [Oregon Health \& Science University, USA]); BRAiNS (Biologically Resilient Adults in Neurological Studies [University of Kentucky, USA]); ROS (Religious Orders Study) + MAPRU (Memory and Aging Project [Rush University, USA]). For a sensitivity analysis, autopsy data for partially missing $(n=77)$ and nonautopsied participants $(n=435)$ were imputed.

probable or possible vascular dementia. Lewy body pathology was seen among $19 \%$ of the participants (204 of 1054), and among them $44.6 \%$ (91 of 204) had neocortical Lewy body disease. Neocortical Lewy body disease among those with clinical $\mathrm{AD}$ was rare when the $\mathrm{AD}$ pathology rating was low but was seen in about $20 \%$ of subjects with clinical $\mathrm{AD}$ when the $\mathrm{AD}$ pathology rating was moderate or severe. Primary age-related tauopathy accounted for $13.5 \%$ (33 of 245) of clinical AD cases. APOE \&4 prevalence increased as the level of AD pathologic burden increased: $12 \%$ among those with low AD pathology, $20 \%$ among those with moderate AD pathology, 36\% among those with high AD pathology without lacunes and large infarcts, and $49 \%$ among those with high AD pathology with lacunes and/or large infarcts. As expected, incident clinical $\mathrm{AD}$ was more likely to have occurred among those with high AD pathology, with more than $50 \%$ of those with high AD pathology diagnosed with clinical $\mathrm{AD}$ during the follow-up.

Table 2

Characteristics of participants who died during follow-up with or without autopsy $(\mathrm{N}=1566)$

\begin{tabular}{|c|c|c|c|c|c|}
\hline Parameters & \multicolumn{2}{|c|}{ With autopsy $(\mathrm{N}=1054)$} & \multicolumn{2}{|c|}{ Without autopsy $(\mathrm{N}=512 *)$} & $P$ value \\
\hline Age at death, y: mean, SD & 88.53 & 7.26 & 89.49 & 7.31 & .014 \\
\hline Women: $n \%$ & 666 & 63.2 & 314 & 61.33 & .48 \\
\hline Race: White \% (vs. non-White) & 1039 & 98.7 & 469 & 91.6 & $<.001$ \\
\hline Duration of follow-up, y: mean, SD & 7.84 & 4.73 & 6.92 & 5.14 & .006 \\
\hline $\begin{array}{l}\text { Duration between last observation to death, } \\
\text { y: mean, SD }\end{array}$ & 0.96 & 1.29 & 1.83 & 2.22 & $<.001$ \\
\hline Centers: $n \%$ & & & & & $<.001$ \\
\hline Oregon & 113 & 10.72 & 190 & 37.11 & \\
\hline Rush & 549 & 52.09 & 114 & 22.27 & \\
\hline
\end{tabular}

Abbreviations: $A P O E$, apolipoprotein E; SD, standard deviation.

*Including a small proportion of subjects $(n=77)$ who had autopsy but missing some of pathology variables of our interests.

${ }^{\dagger}$ Based on univariate analysis. 
Table 3

Logistic regression model with missing autopsy as the outcome

\begin{tabular}{|c|c|c|c|}
\hline Parameter (OR unit difference) & OR & $95 \% \mathrm{CI}$ & $P$ value \\
\hline Age at death (1 y) & 0.98 & $0.96-1.00$ & .02 \\
\hline Female (vs. male) & 0.86 & $0.67-1.11$ & .26 \\
\hline Race (White vs. non-White) & 0.26 & $0.13-0.52$ & $<.01$ \\
\hline Education (1 y) & 0.95 & $0.91-0.99$ & $<.01$ \\
\hline $\begin{array}{l}A P O E \text { (having at least one } \varepsilon 4 \text { allele vs. } \\
\text { no } \varepsilon 4 \text { allele) }\end{array}$ & 1.10 & $0.82-1.47$ & .55 \\
\hline Duration of follow-up (1 y) & 0.98 & $0.96-1.01$ & .23 \\
\hline $\begin{array}{l}\text { Duration from the last observation to } \\
\text { death }(1 \mathrm{y})\end{array}$ & 1.35 & $1.25-1.47$ & $<.0001$ \\
\hline $\begin{array}{l}\text { Onset of clinical AD observed during } \\
\text { the follow-up (vs. censored) }\end{array}$ & 1.06 & $0.76-1.48$ & .73 \\
\hline
\end{tabular}

Abbreviations: AD, Alzheimer's disease; APOE, apolipoprotein E; CI, confidence interval; OR, odds ratio.

NOTE. Center effects were controlled in the model. The number of subjects who did not have autopsy $=435$, the number of subjects who had autopsy $=1131(1054+77)$.

Table 3 shows the logistic regression results for the factors associated with missing autopsy data. Older age at death, White race, and higher education were associated with lower likelihood of missing autopsy, whereas longer duration from the last observation to death was a positive predictor of missing autopsy, confirming that the MAR assumption was reasonable in our data, although we cannot exclude the possibility that the missing data pattern was nonignorable (i.e., informative dropout).

\subsection{Main results}

Education, sex, presence of $A P O E \varepsilon 4$, and Lewy body pathology were controlled for in Model 1 with age as the time scale, and we further added center indicators in Model 2 (Table 4). For each AD pathology level (low, moderate, and high), we assessed whether having lacunes and/or large infarcts posed an excess risk of a clinical diagnosis of AD by comparing the hazard rate for AD pathology only with that for AD pathology with vascular factors. In Model 1, all other pathology patterns showed a higher risk of being diagnosed with clinical $\mathrm{AD}$ in comparison with low $\mathrm{AD}$ pathology without lacunes and large infarcts (reference group), with adjusted hazard ratios (HRs) ranging from 2.6 (moderate AD pathology without lacunes and large infarcts) to 8.6 (high AD pathology without lacunes and large infarcts). The additional risk posed by lacunes or large infarcts was significant among those with low AD pathology $(P=.017)$ and moderate AD pathology $(P=.018)$, but was not significant among those with high AD pathology $(P=.199)$, suggesting that once AD pathology becomes definitive, having lacunes or large infarcts does not add to the risk of being diagnosed with clinical AD. In Model 2, controlling for center effects attenuated the additional risks posed by lacunes and large infarcts. We found an additional risk posed by these vascular factors only among those with low $\operatorname{AD}(P=.012)$. Regarding the center effects, significant variability was found across centers: in comparison with Oregon cohorts (the reference group), the Rush cohort showed a higher likelihood of having incident clinical AD diagnosis (HR $=1.73, P<.01)$, whereas the Washington University cohort showed a lower likelihood $(\mathrm{HR}=0.27, P<.01)$. The Kentucky and Oregon cohorts were similar regarding the risk of incident clinical AD diagnosis. Regarding other covariates, Lewy body pathology was consistently significantly associated with an increased risk of clinical AD regardless of models or with/without imputation with an HR of 1.5. Finally, we calculated PAR\% using the coefficients derived from Table 4 Model 2 , and the prevalence of pathology types reported in Table 1. PAR\% ranged from 14\% (low AD pathology with lacunes and/or large infarcts) to $45 \%$ (high AD pathology without lacunes and large infarcts). Overall, an estimated $89 \%$ of clinical $\mathrm{AD}$ could be eliminated by preventing all five AD pathology patterns (patterns from (2) to (6)). In addition, 9.5\% of clinical AD could be eliminated by preventing Lewy body pathology. Excess risk of clinical AD posed by vascular factors was only significant among the low AD pathology group: the proportion of clinical $\mathrm{AD}$ attributable to lacunes or large infarcts was estimated as $14.3 \%$ or less.

\subsection{Sensitivity analysis using imputed data}

To address potential selection bias from using only autopsied participants, we also imputed pathology types in a sensitivity analysis. The results are listed in Table 4. The imputation did not yield any notable changes to the main results reported in Model 2; again additional HRs (excess risk) associated with lacunes and/or large infarcts were only significant among those with low $\mathrm{AD}$ pathology $(P=.02)$. Using the imputed pathologies, the center effect of Washington University became insignificant, that is, their participants' risk of incident clinical AD was similar to Oregon's.

\subsection{Post hoc analyses}

The six pathology patterns used in the study were based on 1991 criteria of Braak and Braak [17]. Braak et al. modified the criteria for the use of immunohistochemistry [37]; the modified criteria were tested in a large European multicenter study, and it was concluded that at least moderate severity of neuropil threads/NFTs is needed to count an area positive for most Braak stages [38]. Therefore, we limited these analyses to cases autopsied after January 2006 and examined what proportion of those cases with high AD pathology with or without lacunes and large infarcts had clinical diagnosis of AD. Of 104 cases with high AD pathology (pathology patterns (5) and (6) defined here), $73 \%$ ( $n=76$ ) had diagnosis of clinical AD and additional $13 \%(n=14)$ had other types of dementia (vascular, dementia with Lewy bodies, and frontotemporal dementia). Cox proportional hazard models were also run using only subjects autopsied after 2006. The results are included in Supplementary Table 1. The HRs for AD pathology increased in magnitude, indicating closer correspondence between AD pathology and clinical diagnosis of AD. The results regarding contribution of lacunes and large infarcts remained unchanged. 
Table 4

Results of Cox proportional hazard model with pathology patterns as independent variables with outcomes being incidence of clinical AD

\begin{tabular}{|c|c|c|c|c|c|c|c|}
\hline \multirow[b]{3}{*}{ Parameter } & \multicolumn{4}{|c|}{ Using observed data only } & \multicolumn{2}{|c|}{ Including imputed data } & \multirow{3}{*}{$\begin{array}{l}\text { PAR\% based on } \\
\text { Model } 2 \text { and } \\
\text { observed } \\
\text { prevalence }\end{array}$} \\
\hline & \multicolumn{2}{|l|}{ Model 1} & \multicolumn{2}{|l|}{ Model 2} & \multirow{2}{*}{$\begin{array}{l}\text { Hazard ratio } \\
(95 \% \mathrm{CI}) \\
\text { sensitivity } \\
\text { analysis }\end{array}$} & \multirow[b]{2}{*}{$\begin{array}{l}\text { Difference in coefficient, } \\
P \text { value }\end{array}$} & \\
\hline & $\begin{array}{l}\text { Hazard ratio } \\
(95 \% \mathrm{CI})\end{array}$ & $\begin{array}{l}\text { Difference in } \\
\text { coefficient, } \\
P \text { value }\end{array}$ & $\begin{array}{l}\text { Hazard ratio } \\
(95 \% \mathrm{CI})\end{array}$ & $\begin{array}{l}\text { Difference in } \\
\text { coefficient, } \\
P \text { value }\end{array}$ & & & \\
\hline Female (vs. male) & $1.02(0.77-1.35)$ & & $0.91(0.68-1.22)$ & & $0.95(0.75-1.19)$ & & \\
\hline Education (1 y) & $1.07(1.03-1.11)^{*}$ & & $1.03(0.99-1.07)$ & & $1.02(0.99-1.05)$ & & \\
\hline $\begin{array}{l}A P O E \varepsilon 4 \text { (having at least one } \varepsilon 4 \text { allele vs. } \\
\text { no } \varepsilon 4 \text { allele) }\end{array}$ & $1.34(0.99-1.81)$ & & $1.36(1.00-1.85)^{\dagger}$ & & $1.42(1.12-1.80)^{*}$ & & \\
\hline Lewy body pathology (yes vs. no) & $1.59(1.20-2.11)^{*}$ & & $1.54(1.16-2.05)^{*}$ & & $1.49(1.19-1.87)^{*}$ & & $9.5 \%$ \\
\hline \multicolumn{8}{|l|}{ Pathology patterns } \\
\hline $\begin{array}{l}\text { (1) Low AD pathology without lacunes and } \\
\text { large infarcts }\end{array}$ & Ref & (1) vs. (2), $P=.017^{\dagger}$ & Ref & (1) vs. (2), $P=.012^{\dagger}$ & Ref & (1) vs. (2), $P=.020^{\dagger}$ & Ref \\
\hline $\begin{array}{l}\text { (2) Low AD pathology with lacunes and/or } \\
\text { large infarcts }\end{array}$ & $3.03(1.20-7.64)^{\dagger}$ & & $3.19(1.27-8.05)^{\dagger}$ & & $2.38(1.16-4.87)^{\dagger}$ & & $14.3 \%$ \\
\hline $\begin{array}{l}\text { (3) Moderate AD pathology without lacunes } \\
\text { and large infarcts }\end{array}$ & $2.55(1.15-5.69)^{\dagger}$ & (3) vs. (4), $P=.018^{\dagger}$ & $2.04(0.91-4.57)$ & (3) vs. (4), $P=.115$ & $1.89(1.00-3.62)^{\dagger}$ & (3) vs. (4), $P=.190$ & $35.8 \%$ \\
\hline $\begin{array}{l}\text { (4) Moderate AD pathology with lacunes } \\
\text { and/or large infarcts }\end{array}$ & $3.90(1.76-8.63)^{*}$ & & $2.72(1.22-6.06)^{\dagger}$ & & $2.39(1.27-4.49)^{\dagger}$ & & $43.5 \%$ \\
\hline $\begin{array}{l}\text { (5) High AD pathology without lacunes and } \\
\text { large infarcts }\end{array}$ & $8.57(3.82-19.22)^{*}$ & (5) vs. (6), $P=.199$ & $6.82(3.03-15.38)^{*}$ & (5) vs. (6), $P=.504$ & $5.30(2.60-10.78)^{*}$ & (5) vs. (6), $P=.930$ & $45.2 \%$ \\
\hline $\begin{array}{l}\text { (6) High AD pathology with lacunes and/or } \\
\text { large infarcts }\end{array}$ & $6.55(2.86-14.99)^{*}$ & & $5.91(2.57-13.61)^{*}$ & & $5.41(2.60-9.75)^{*}$ & & $33.4 \%$ \\
\hline $\begin{array}{l}\text { Combined PAR }{ }^{\ddagger} \text { (pathologic patterns (2), (3), } \\
\text { (4), (5), and (6)) }\end{array}$ & & & & & & & $88.7 \%$ \\
\hline \multicolumn{8}{|l|}{ Center effects } \\
\hline Oregon & & & Ref & & Ref & & \\
\hline Rush & & & $1.73(1.16-2.59)^{*}$ & & $1.67(1.25-2.23)^{*}$ & & \\
\hline Washington $\mathrm{U}$ & & & $0.27(0.13-0.57)^{*}$ & & $0.81(0.54-1.21)$ & & \\
\hline Kentucky & & & $0.82(0.51-1.31)$ & & $1.08(0.76-1.53)$ & & \\
\hline
\end{tabular}

Abbreviations: AD, Alzheimer's disease; APOE, apolipoprotein E; CI, confidence interval; PAR, Population Attributable Risk.

NOTE. PAR $\%$ was calculated by using formula: (prevalence $X(R R-1)) /(1+($ prevalence $X(R R-1)))$.

$* P<.01$.

${ }^{\dagger} P<05$

${ }^{\ddagger}$ Calculated using the formula: $P A R_{\text {Combined }}=1-\prod_{\text {pattern }=2}^{6}\left(1-P A R_{\text {pattern }}\right)$. 
To delineate further the effect of vascular factors on clinical dementia incidence, we ran an additional model with the outcome of overall dementia using observed data (Table 5). Lacunes and large infarcts posed excess risk among those with low AD pathology $(P=.01)$ and those with moderate AD pathology $(P=.04)$. The HRs ranged from 1.81 (moderate AD pathology without lacunes or large infarcts) to 6.11 (high AD pathology without lacunes or large infarcts). Up to $34 \%$ of overall dementia could be eliminated by preventing lacunes and large infarcts based on the PAR\% using HRs for which the vascular contribution was shown to be significant. Combined PAR\% showed that about $74 \%$ of overall clinical dementia could be eliminated by preventing AD pathology patterns examined here, and an additional $10 \%$ could be eliminated by preventing Lewy body pathology.

\section{Discussion}

There is growing interest in the influence of vascular factors on clinical AD incidence [3-12]. Using harmonized pathology data derived from well-characterized community cohorts followed at ADCs in the United States, we assessed whether coexistence of vascular factors posed additional risk of an incident clinical diagnosis of AD beyond the risk associated with AD pathology, and to what extent clinical diagnosis of $\mathrm{AD}$ could be prevented by eliminating lacunes and large infarcts. There are several noteworthy findings.

First, the prevalence of clinically diagnosed $\mathrm{AD}$ increased as the severity of AD pathology increased from $4.2 \%$ (among low $\mathrm{AD}$ pathology group) to 53.3\% (among high AD pathology group), showing high correlations of plaques and tangles with overall clinical $\mathrm{AD}$ incidence. Yet about half of the participants died without clinical AD diagnosis, despite having high AD pathology. This result coincides with previous studies among community samples [14,39], showing between one-third and one-half of community samples may die without having a clinical AD diagnosis, despite autopsy findings of moderate or high $\mathrm{AD}$ pathology. Ours and these latter studies are based on 1991 Braak criteria [17]. Limiting the samples to those autopsied after 2006, that is, the cases likely assessed based on newer criteria [37], we found a higher proportion (73\%) of those with high $\mathrm{AD}$ pathology had clinical diagnosis of $\mathrm{AD}$. This proportion is still lower than those found among clinical samples [40]. This discrepancy may be, in part, because of the fact that some cases after 2006 were still measured by the older Braak criteria. It is also possible that our study subjects were drawn from highly educated and healthy volunteers who likely had increased cognitive reserve relative to clinical samples. In addition, informants were not always available in the community samples, which might have led to an underestimation of cognitive problems. All explanations are limited to speculations at this point.

One important question is whether these participants with moderate and high $\mathrm{AD}$ pathology would have been diagnosed with clinical AD during their lifetime, had they lived longer. In our imputed data, we found that $40.8 \%$ of those with moderate or high $\mathrm{AD}$ pathology without an observed diagnosis of clinical AD or dementia had an imputed age of $\mathrm{AD}$ onset within 3 years after their date of death. In other words, we estimated

Table 5

Results of Cox proportional hazard model with pathology patterns as independent variables with outcomes being incidence of overall dementia

\begin{tabular}{|c|c|c|c|}
\hline Parameter & \multicolumn{3}{|l|}{ Using observed data only } \\
\hline Education (1 y) & $1.02(0.99-1.06)$ & & \\
\hline$A P O E \varepsilon 4$ (having at least one $\varepsilon 4$ allele vs. no $\varepsilon 4$ allele) & $1.37(1.04-1.82)^{*}$ & & \\
\hline Lewy body pathology (yes vs. no) & $1.57(1.21-2.04)^{\dagger}$ & & $9.9 \%$ \\
\hline (2) Low AD pathology with lacunes and/or large infarcts & $2.77(1.26-6.10)^{*}$ & & $6.1 \%$ \\
\hline (3) Moderate AD pathology without lacunes and large infarcts & $1.81(0.92-3.59)$ & (3) vs. (4), $P=.042 \%$ & $21.0 \%$ \\
\hline (4) Moderate AD pathology with lacunes and/or large infarcts & $2.56(1.30-5.05)^{\dagger}$ & & $28.3 \%$ \\
\hline (5) High AD pathology without lacunes and large infarcts & $6.11(3.06-12.20)^{\dagger}$ & (5) vs. (6), $P=.678$ & $33.8 \%$ \\
\hline (6) High AD pathology with lacunes and/or large infarcts & $5.64(2.78-11.42)^{\dagger}$ & & $25.6 \%$ \\
\hline $\begin{array}{l}\text { Combined PAR (pathology patterns (2), (3), (4), (5), and } \\
\text { (6) listed previously) }\end{array}$ & & & $73.8 \%$ \\
\hline Washington $\mathrm{U}$ & $0.73(0.44-1.20)$ & & \\
\hline Kentucky & $0.99(0.65-1.51)$ & & \\
\hline
\end{tabular}

Abbreviations: AD, Alzheimer's disease; APOE, apolipoprotein E; CI, confidence interval; PAR, Population Attributable Risk.

NOTE. PAR\% was calculated by using formula: (prevalence $X(R R-1)) /(1+($ prevalence $X(R R-1))$ ).

$* P<.05$.

${ }^{\dagger} P<.01$.

${ }^{\ddagger}$ Calculated using the formula: $P A R_{\text {Combined }}=1-\prod_{\text {type }=2}^{6}\left(1-P A R_{\text {type }}\right)$. 
that $40 \%$ of participants who died without a clinical AD diagnosis, despite having moderate or high $\mathrm{AD}$ pathology, would have been diagnosed if they had lived longer. If life expectancy among the oldest old age group increases, the prevalence of $\mathrm{AD}$ could increase sharply unless advances in the prevention and treatment of $\mathrm{AD}$ are also made. Regarding the PAR\%, an estimated $89 \%$ of incident clinical AD cases could be prevented by eliminating $\mathrm{AD}$ pathology, either alone or in combination with lacunar and large infarcts. The PAR\% estimates of the moderate and high AD pathology groups were similar because of higher prevalence of those with moderate AD pathology despite their lower hazard of clinical AD. Regarding overall dementia (i.e., including all subtypes of dementia), $75 \%$ of incident cases could be prevented by eliminating $\mathrm{AD}$ pathology. We expect the contribution of vascular factors on vascular dementia incidence is large, but our small sample size precluded us from estimating HRs using vascular dementia as the outcome.

Second, in the harmonized data used in this study, the mean age at death was about 90 years, and the excess risk of clinical $\mathrm{AD}$ posed by the coexistence of lacunes and large infarcts was relatively small; a significant contribution was only observed among those with low AD pathology. It is well established that the prevalence of mixed dementia increases as age increases [5,12,13,41-43]. However, we found having AD pathology without lacunes and large infarcts was more prevalent in the participants examined here, with $60 \%$ having AD pathology (combining low, moderate, and high) without lacunes or large infarcts in comparison to $40 \%$ with these vascular factors. Meta-analyses of epidemiologic studies have shown that vascular diseases and vascular disease risk factors in midlife are risk factors of $\mathrm{AD}$ in later life $[1,2,4]$. Clinical expression of $\mathrm{AD}$ could be promoted via cardiovascular and cerebrovascular diseases, possibly because of reduced cognitive reserve, but the vascular and $\mathrm{AD}$ pathologic developments could be independent [44-46], although the latter has not been proven. Our results support previous findings $[47,48]$ that reinforced the diagnostic importance of $\mathrm{AD}$ pathology in clinical $\mathrm{AD}$ and a more recent finding among those aged 90 years and older [49]. It is possible that clinicians tend to give a diagnosis of possible vascular dementia if they see lacunes and especially large infarcts on neuroimaging, which may underestimate the vascular contribution of clinical AD. Incidence of vascular dementia in our data was relatively low (about $12 \%$ of those diagnosed with any dementia were diagnosed with vascular dementia), limiting the overall contribution of lacunes and large infarcts at population level. Our finding that the significant additional risk posed by lacunes and large infarcts occurred only among those with low AD pathology also confirms earlier findings by Boyle et al. (e.g., Fig. 3 in [50]) and Schneider et al. (Figs. 1 and 2 in [51]), where the authors found that the variability of cognitive decline explained by vascular factors was more prominent when the severity of $\mathrm{AD}$ pathologies was lower. If the presence of vascular pathology promotes the accumulation of AD pathology [52,53], then the underlying contribution of vascular factors on overall $\mathrm{AD}$ incidence is much higher. However, this causal relation cannot be ascertained using our data set because autopsy data cannot provide the time order of pathologic events. One notable limitation in our analysis is that we did not examine microinfarcts [54] because of the necessity to harmonize data across sites, which could have led to an underestimation of the prevalence of vascular factors. Further harmonization of assessment approaches for microinfarcts and other vascular markers in our data could address this issue in the future [54].

Third, about $15 \%(n=167)$ of participants had low AD pathology without lacunes or large infarcts, and among them 21 ( $2 \%$ of the total) were found to have no NFTs and no neuritic plaques (data not shown), confirming that even among our participants, who had a mean age of 90 years at death, it was possible, if rare, to remain free from these pathologies. Comparing these participants with others regarding their genetic, premorbid neuroimaging, and other biomarker results could reveal some key factors relating to aging free from $\mathrm{AD}$ pathologic development.

Fourth, we found significant center effects. The cohorts followed by Rush University (located in Chicago, IL, USA) had a higher hazard of diagnosed AD compared with the cohorts followed in Oregon (located in Portland, OR, USA) and Kentucky (located in Lexington, KY, USA), whereas the Washington University cohort (located in St. Louis, MO, USA) had a lower hazard of incident AD, although the latter was not found when using imputed data. These differences were seen after controlling for pathologic characteristics, that is, given the same levels of AD pathology, lacunes and large infarcts, Lewy body pathology, and $A P O E \varepsilon 4$ contributions. Unlike the diagnosis of MCI, the diagnostic procedure of $\mathrm{AD}$ is well harmonized across centers, but there may still be some variability depending on, for example, whether biomarker information was used in consensus diagnoses. The center differences could also be because of differences in susceptibility to AD symptoms by cohort, including racial compositions and lifestyle factors and environment.

Finally, selection bias in the autopsied group could distort study results. For example, if those who die without dementia are less likely to come to autopsy, then this could potentially overestimate the association between pathology and $\mathrm{AD}$ incidence. In the present study, using imputed pathology data did not change the main results. The magnitude of bias associated with missing autopsy data is likely to depend on the cohorts examined in the study. We advise researchers to conduct sensitivity analyses when analyzing autopsy data to examine the potential selection bias.

Limitations of this study include all cohorts included in this study are community-based, but they are not a random sample of the community. Generalizability of the results may be limited. Data harmonization requirements excluded some variables from the analyses that were found to explain variability in cognitive decline in other articles, including hippocampal sclerosis $[47,55,56]$, TDP-43 proteinopathy [55-57], microinfarcts [54], cerebral amyloid angiopathy [58], and arteriolosclerosis and atherosclerosis [59]. We could not differentiate the location of infarcts and its effects on clinical diagnosis of AD. Despite 
these shortcomings, the data used here have the advantage of providing a relatively large sample size, adequate longitudinal follow-up, and multicenter data not limited to a specific geographic region, which increases generalizability. Continuation and expansion of the pathology consortium and improvement of standardized neuropathologic assessment criteria are strongly encouraged to further advance our understanding of biological mechanisms and cognitive functions over time.

\section{Acknowledgments}

This study was supported by the National Institute on Aging Funding including R01 AG038651, P30 AG008017, K25 AG043546, P30 AG028383, P30 AG010161, R01 AG015819, R01 AG017917, P50 AG005681, R01 AG034119, P50AG005681, P01AG003991 and P30 AG053760P30.

\section{Supplementary data}

Supplementary data related to this article can be found at http://dx.doi.org/10.1016/j.jalz.2016.11.003.

\section{RESEARCH IN CONTEXT}

1. Systematic review: The presence of cerebrovascular pathology may increase the risk of clinical diagnosis of AD. We assessed the Population Attributable Risk $\%$ of lacunes and large infracts on receiving probable or possible $\mathrm{AD}$ diagnosis (clinical $\mathrm{AD}$ ) during lifetime. Using MEDLINE, we reviewed studies that addressed associations between the clinical diagnosis of $\mathrm{AD}$ and vascular factors. We focused on the presence of lacunes and large infracts confirmed at autopsy. We conducted sensitivity analyses by imputing missing pathology and clinical data to address potential bias because of using only autopsied cases.

2. Interpretation: The coexistence of lacunes and large infarcts results in higher likelihood of clinical diagnosis of $\mathrm{AD}$ only when $\mathrm{AD}$ pathology burden is low. The proportion of clinical AD attributable to lacunes or large infarcts was estimated as $14.3 \%$ or less. About $89 \%$ of clinical AD could be eliminated by preventing $\mathrm{AD}$ pathology. Our results reinforce the diagnostic importance of AD pathology in clinical AD.

3. Future directions: Because of limitations of multicenter data harmonization, the analysis did not examine microinfarcts or other types of vascular pathology. This may have led to an underestimation of the prevalence of vascular factors. Further harmonization of assessment approaches for these vascular markers is required.

\section{References}

[1] Barnes DE, Yaffe K. The projected effect of risk factor reduction on Alzheimer's disease prevalence. Lancet Neurol 2011;10:819-28.

[2] Ritchie K, Ritchie CW, Jaffe K, Skoog I, Scarmeas N. Is late-onset Alzheimer's disease really a disease of midlife? Alzheimers Dement Transl Res Clin Interv 2015;1:122-30.

[3] Dodge HH, Chang CC, Kamboh MI, Ganguli M. Risk of Alzheimer's disease incidence attributable to vascular disease in the population. Alzheimers Dement 2011;7:356-60.

[4] Norton S, Matthews FE, Barnes DE, Yaffe K, Brayne C. Potential for primary prevention of Alzheimer's disease: an analysis of populationbased data. Lancet Neurol 2014;13:788-94.

[5] Viswanathan A, Rocca WA, Tzourio C. Vascular risk factors and dementia: how to move forward? Neurology 2009;72:368-74.

[6] Gorelick PB, Scuteri A, Black SE, Decarli C, Greenberg SM, Iadecola C, et al. Vascular contributions to cognitive impairment and dementia: a statement for healthcare professionals from the American Heart Association/American Stroke Association. Stroke 2011; 42:2672-713.

[7] Unverzagt FW, McClure LA, Wadley VG, Jenny NS, Go RC, Cushman M, et al. Vascular risk factors and cognitive impairment in a stroke-free cohort. Neurology 2011;77:1729-36.

[8] Lorius N, Locascio JJ, Rentz DM, Johnson KA, Sperling RA, Viswanathan A, et al. Vascular disease and risk factors are associated with cognitive decline in the Alzheimer disease spectrum. Alzheimer Dis Assoc Disord 2014;29:18-25.

[9] Deschaintre Y, Richard F, Leys D, Pasquier F. Treatment of vascular risk factors is associated with slower decline in Alzheimer disease. Neurology 2009;73:674-80.

[10] Launer LJ, Petrovitch H, Ross GW, Markesbery W, White LR. AD brain pathology: vascular origins? Results from the HAAS autopsy study. Neurobiol Aging 2008;29:1587-90.

[11] Kawas CH, Kim RC, Sonnen JA, Bullain SS, Trieu T, Corrada MM. Multiple pathologies are common and related to dementia in the oldest-old: the 90+ Study. Neurology 2015;85:535-42.

[12] Ganguli M, Rodriguez E. Age, Alzheimer's disease, and the big picture. Int Psychogeriatr 2011;23:1531-4.

[13] Schneider JA, Arvanitakis Z, Bang W, Bennett DA. Mixed brain pathologies account for most dementia cases in community-dwelling older persons. Neurology 2007;69:2197-204.

[14] Sonnen JA, Santa Cruz K, Hemmy LS, Woltjer R, Leverenz JB, Montine KS, et al. Ecology of the aging human brain. Arch Neurol 2011;68:1049-56.

[15] Abner EL, Schmitt FA, Nelson PT, Lou W, Wan L, Gauriglia R, et al. The Statistical Modeling of Aging and Risk of Transition Project: data collection and harmonization across 11 longitudinal cohort studies of aging, cognition, and dementia. Obs Stud 2015;1:56-73.

[16] Mirra SS, Heyman A, McKeel D, Sumi SM, Crain BJ, Brownlee LM, et al. The Consortium to Establish a Registry for Alzheimer's Disease (CERAD). Part II. Standardization of the neuropathologic assessment of Alzheimer's disease. Neurology 1991;41:479-86.

[17] Braak H, Braak E. Neuropathological stageing of Alzheimer-related changes. Acta Neuropathol 1991;82:239-59.

[18] Green MS, Kaye JA, Ball MJ. The Oregon brain aging study: neuropathology accompanying healthy aging in the oldest old. Neurology 2000;54:105-13.

[19] Kaye J, Michael Y, Calvert J, Leahy M, Crawford D, Kramer P. Exceptional brain aging in a rural population-based cohort. J Rural Health 2009;25:320-5.

[20] Bennett DA, Schneider JA, Arvanitakis Z, Wilson RS. Overview and findings from the religious orders study. Curr Alzheimer Res 2012; 9:628-45.

[21] Bennett DA, Schneider JA, Buchman AS, Barnes LL, Boyle PA, Wilson RS. Overview and findings from the Rush Memory and Aging Project. Curr Alzheimer Res 2012;9:646-63. 
[22] Berg L, McKeel DW Jr, Miller JP, Storandt M, Rubin EH, Morris JC, et al. Clinicopathologic studies in cognitively healthy aging and Alzheimer's disease: relation of histologic markers to dementia severity, age, sex, and apolipoprotein E genotype. Arch Neurol 1998;55:326-35.

[23] Schmitt FA, Nelson PT, Abner E, Scheff S, Jicha GA, Smith C, et al. University of Kentucky Sanders-Brown healthy brain aging volunteers: donor characteristics, procedures and neuropathology. Curr Alzheimer Res 2012;9:724-33.

[24] Beekly DL, Ramos EM, van Belle G, Deitrich W, Clark AD, Jacka ME, et al. The National Alzheimer's Coordinating Center (NACC) Database: an Alzheimer disease database. Alzheimer Dis Assoc Disord 2004;18:270-7.

[25] American Psychiatric Association. Diagnostic and statistical manual of mental disorders. 3rd ed. Washington, DC: American Psychiatric Association; 1987. revised.

[26] American Psychiatric Association. Diagnostic and statistical manual of mental disorders. 4th ed. Washington, DC: American Psychiatric Association; 1994.

[27] McKhann G, Drachman D, Folstein M, Katzman R, Price D, Stadlan EM. Clinical diagnosis of Alzheimer's disease: report of the NINCDS-ADRDA Work Group under the auspices of Department of Health and Human Services Task Force on Alzheimer's Disease. Neurology 1984;34:939-44.

[28] Kleinbaum D, Klein M. Survival analysis: a self-learning text. New York: Springer; 2005.

[29] Rubin DB. Multiple imputation for nonresponse in surveys. New York: John Wiley \& Sons, Inc.; 1987.

[30] Raghunathan TE, Lepkowski JM, Hoewyk JV, Solenberger P. A multivariate technique for multiply imputing missing values using a sequence of regression models. Surv Methodol 2001;27:85-95.

[31] He Y, Yucel R, Raghunathan TE. A functional multiple imputation approach to incomplete longitudinal data. Stat Med 2011;30:1137-56.

[32] Taylor JM, Cooper KL, Wei JT, Sarma AV, Raghunathan TE, Heeringa SG. Use of multiple imputation to correct for nonresponse bias in a survey of urologic symptoms among African-American men. Am J Epidemiol 2002;156:774-82.

[33] Burgette LF, Reiter JP. Multiple imputation for missing data via sequential regression trees. Am J Epidemiol 2010;172:1070-6.

[34] McKeith IG, Dickson DW, Lowe J, Emre M, O'Brien JT, Feldman H, et al. Diagnosis and management of dementia with Lewy bodies: third report of the DLB Consortium. Neurology 2005;65:1863-72.

[35] Beach TG, Adler CH, Lue L, Sue LI, Bachalakuri J, Henry-Watson J, et al. Unified staging system for Lewy body disorders: correlation with nigrostriatal degeneration, cognitive impairment and motor dysfunction. Acta Neuropathol 2009;117:613-34.

[36] Crary JF, Trojanowski JQ, Schneider JA, Abisambra JF, Abner EL, Alafuzoff I, et al. Primary age-related tauopathy (PART): a common pathology associated with human aging. Acta Neuropathol 2014; 128:755-66.

[37] Braak H, Alafuzoff I, Arzberger T, Kretzschmar H, Del Tredici K. Staging of Alzheimer disease-associated neurofibrillary pathology using paraffin sections and immunocytochemistry. Acta Neuropathol 2006;112:389-404.

[38] Alafuzoff I, Arzberger T, Al-Sarraj S, Bodi I, Bogdanovic N, Braak H, et al. Staging of neurofibrillary pathology in Alzheimer's disease: a study of the BrainNet Europe Consortium. Brain Pathol 2008;18:484-96.

[39] Neuropathology Group. Medical Research Council Cognitive F, Aging S. Pathological correlates of late-onset dementia in a multicentre, community-based population in England and Wales. Neuropathology Group of the Medical Research Council Cognitive Function and Ageing Study (MRC CFAS). Lancet 2001;357:169-75.
[40] Hyman BT, Phelps CH, Beach TG, Bigio EH, Cairns NJ, Carrillo MC, et al. National Institute on Aging-Alzheimer's Association guidelines for the neuropathologic assessment of Alzheimer's disease. Alzheimers Dement 2012;8:1-13.

[41] Langa KM, Foster NL, Larson EB. Mixed dementia: emerging concepts and therapeutic implications. JAMA 2004;292:2901-8.

[42] Rockwood K. Mixed dementia: Alzheimer's and cerebrovascular disease. Int Psychogeriatr 2003;15(Suppl 1):39-46.

[43] Stricker NH, Dodge HH, Dowling NM, Han SD, Erosheva EA, Jagust WJ. CSF biomarker associations with change in hippocampal volume and precuneus thickness: implications for the Alzheimer's pathological cascade. Brain Imaging Behav 2012;6:599-609.

[44] Abner EL, Nelson PT, Kryscio RJ, Schmitt FA, Fardo DW, Woltjer RL, et al. Diabetes is associated with cerebrovascular but not Alzheimer neuropathology. Alzheimers Dement 2016;12:882-9.

[45] Petrovitch H, Ross GW, Steinhorn SC, Abbott RD, Markesbery W, Davis $\mathrm{D}$, et al. AD lesions and infarcts in demented and nondemented Japanese-American men. Ann Neurol 2005;57:98-103.

[46] Lo RY, Jagust WJAlzheimer's Disease Neuroimaging Initiative. Vascular burden and Alzheimer disease pathologic progression. Neurology 2012;79:1349-55.

[47] Chui HC, Zarow C, Mack WJ, Ellis WG, Zheng L, Jagust WJ, et al. Cognitive impact of subcortical vascular and Alzheimer's disease pathology. Ann Neurol 2006;60:677-87.

[48] Nelson PT, Jicha GA, Schmitt FA, Liu H, Davis DG, Mendiondo MS, et al. Clinicopathologic correlations in a large Alzheimer disease center autopsy cohort: neuritic plaques and neurofibrillary tangles "do count" when staging disease severity. J Neuropathol Exp Neurol 2007;66:1136-46.

[49] Brookmeyer R, Kawas CH, Abdallah N, Paganini-Hill A, Kim RC, Corrada MM. Impact of interventions to reduce Alzheimer's disease pathology on the prevalence of dementia in the oldest-old. Alzheimers Dement 2016;12:225-32.

[50] Boyle PA, Wilson RS, Yu L, Barr AM, Honer WG, Schneider JA, et al. Much of late life cognitive decline is not due to common neurodegenerative pathologies. Ann Neurol 2013;74:478-89.

[51] Schneider JA, Arvanitakis Z, Yu L, Boyle PA, Leurgans SE, Bennett DA. Cognitive impairment, decline and fluctuations in older communitydwelling subjects with Lewy bodies. Brain 2012;135:3005-14.

[52] de la Torre JC. Vascular basis of Alzheimer's pathogenesis. Ann N Y Acad Sci 2002;977:196-215.

[53] Kalaria RN, Akinyemi R, Ihara M. Does vascular pathology contribute to Alzheimer changes? J Neurol Sci 2012;322:141-7.

[54] Smith EE, Schneider JA, Wardlaw JM, Greenberg SM. Cerebral microinfarcts: the invisible lesions. Lancet Neurol 2012;11:272-82.

[55] Nag S, Yu L, Capuano AW, Wilson RS, Leurgans SE, Bennett DA, et al. Hippocampal sclerosis and TDP-43 pathology in aging and Alzheimer disease. Ann Neurol 2015;77:942-52.

[56] Nelson PT, Abner EL, Schmitt FA, Kryscio RJ, Jicha GA, Smith CD, et al. Modeling the association between 43 different clinical and pathological variables and the severity of cognitive impairment in a large autopsy cohort of elderly persons. Brain Pathol 2010;20:66-79.

[57] Wilson AC, Dugger BN, Dickson DW, Wang DS. TDP-43 in aging and Alzheimer's disease-a review. Int J Clin Exp Pathol 2011;4:147-55.

[58] Boyle PA, Yu L, Nag S, Leurgans S, Wilson RS, Bennett DA, et al. Cerebral amyloid angiopathy and cognitive outcomes in communitybased older persons. Neurology 2015;85:1930-6.

[59] Arvanitakis Z, Capuano AW, Leurgans SE, Bennett DA, Schneider JA. Relation of cerebral vessel disease to Alzheimer's disease dementia and cognitive function in older persons: a cross-sectional study. Lancet Neurol 2016;15:934-43. 